\title{
Volver a lo básico
}

\author{
Back to the basics \\ Voltar ao básico
}

Lina María Sierra Tobón*

https://doi.org/10.35454/rncm.v4supl1.342

El 30 de junio del 2000 recibí el diploma que certifica mi formación profesional como Nutricionista-Dietista, ese día brindé por lo que pensé era el final, sin comprender para entonces que apenas era el comienzo.

Han pasado 21 años y, aunque el final se ve lejano, cada vez me inquieta menos; por el contrario, el entusiasmo está centrado ahora en la posibilidad de volver a lo básico, claro está, sin comenzar de nuevo. Y es que lo básico, entendido como lo fundamental (lo primero) y no solo como lo elemental (lo más sencillo), puede dar respuesta a muchas de aquellas inquietudes que con el tiempo quedan en el tintero. Estamos de acuerdo en que lo básico para mí no necesariamente lo es para usted, pero cuando hablamos de un colectivo de personas que hemos optado por una formación profesional en nutrición, es posible encontrar un punto de convergencia que nos permita partir de un interés común.

\section{EL CUIDADO NUTRICIONAL COMO INTERÉS COMÚN}

De acuerdo con Ester Busquets ${ }^{(1)}$, el cuidado es una característica inherente al ser humano. La autora señala que "si no cuidamos y no nos cuidan cuando lo necesitamos, si no nos sentimos responsables frente a la vulnerabilidad ajena, se quebrantan los cimientos de las profesiones de cuidado, y naturalmente también los cimientos de la humanidad".

No en vano, a partir de la Declaración Internacional de Cartagena sobre el Derecho al Cuidado Nutricional y la

*Correspondencia: Lina María Sierra Tobón. integralclinicalnutrition@gmail.com
Lucha contra la Malnutrición ${ }^{(2)}$ se ha instaurado en diferentes espacios de formación académica el cuidado nutricional como la razón de ser de quienes compartimos el gusto por la nutrición; es así como a través de trece principios se proporciona un marco de referencia que promueve el cuidado nutricional y permite que la persona enferma reciba terapia nutricional en condición de dignidad.

Si lo extrapolamos a la situación de salud actual, en la que la pandemia nos ha permitido de alguna manera ser más reflexivos, podemos encontrar sentido al cuidado como punto de convergencia. En palabras de Busquets ${ }^{(1)}$, "La sociedad confía en que, pase lo que pase en la vida de quienes la integran, los profesionales de la salud estarán allí para cuidarlos"; y es que eso es lo que somos: profesionales de la salud, y eso es lo que hacemos: cuidar.

Nos hemos formado para ser responsables del cuidado nutricional de nuestro paciente y nos seguimos preparando para cuidar de su alimentación de la mejor manera posible, leemos publicaciones basadas en evidencia científica, lideramos investigaciones que construyen conocimiento, participamos en seminarios académicos, asistimos a cursos de actualización e incluso realizamos posgrados que nos den la tranquilidad de saber que lo que hacemos lo estamos haciendo bien.

Hemos comprendido que el cuidado nutricional corresponde a un derecho humano emergente estrechamente ligado a derechos humanos fundamentales como el derecho a la alimentación, el derecho a la salud y, por supuesto, el derecho a la vida, asumiendo con responsabilidad y entereza un papel protagónico frente al oportuno y adecuado manejo nutricional de nuestro paciente.

No obstante, la invitación a través de esta edición especial sobre Bioética y Derechos Humanos en Nutrición 
Clínica pretende ir más allá de la formación académica y, como se planteó inicialmente, volver a la básico y abordar de manera ética temas coyunturales que se encuentran en relación directa con el cuidado nutricional y que orientan las posibles respuestas ante diversas situaciones no solo desde el saber sino también desde el ser.

\section{LA ÉTICA DEL CUIDADO}

La ética, entendida como una disciplina que se ocupa de evaluar nuestras acciones, es parte fundamental de la formación profesional. De acuerdo con Valera ${ }^{(3)}$, "la ética no es arbitraria, es una disciplina racional con verdades universales, pero que se aplica de modo diverso en las distintas áreas del quehacer".

En el ejercicio de la nutrición clínica, la ética aplicada permite proponer recomendaciones para la acción, que como se ha mencionado, está fundamentada en el cuidado nutricional de aquella persona en condición de vulnerabilidad desde el punto de vista nutricional.

Busquets señala lo siguiente ${ }^{(1)}$ : "la vulnerabilidad inherente a la naturaleza humana precisa del cuidado como respuesta ética a esa precariedad. La ética del cuidado es el esfuerzo de fundamentar la respuesta ética ante la fragilidad".

Debido a que el cuidado nutricional se considera un punto convergente en la formación del nutricionista, es necesario que este se lleve a cabo guiado por principios y normas que permitan ejercer la profesión con rigurosidad ética y científica.

La presente edición reúne a profesionales que abordan temas de actualidad desde un enfoque ético invitándonos a cuidar de lo que somos, cuidar de lo que hacemos,

cuidar de nuestra profesión y de quienes la ejercen y, por supuesto, cuidar de nuestros pacientes cuya manifiesta vulnerabilidad no espera de nosotros una respuesta diferente al cuidado.

Finalmente, si como nutricionistas reconocemos el cuidado nutricional como la esencia de nuestro ethos profesional será posible volver a lo básico sin comenzar de nuevo y parafraseando una vieja reflexión en torno a la medicina: prepararnos no solo para ser buenos nutricionistas sino también para ser nutricionistas buenos.

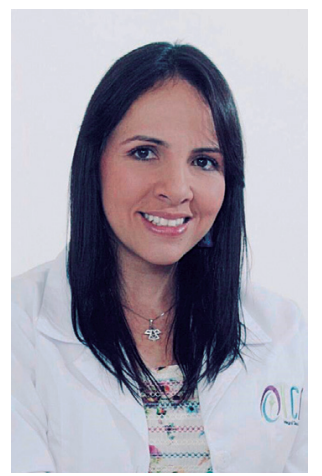

\section{Referencias bibliográficas}

1. Busquets Alibés E. Ética del cuidado en ciencias de la salud: a partir de la lectura de La muerte de Iván Ilich de Lev Tolstói. Barcelona: Herder; 2019.

2. Cárdenas D, Bermúdez C, Echeverri S, Pérez A, Puentes M, López L, et al. Declaración de Cartagena. Declaración Internacional sobre el Derecho al Cuidado Nutricional y la Lucha contra la Malnutrición. Nutr Hosp. 2019;36(4):97480. doi: 10.20960/nh.02701.

3. Valera L, Carrasco MA. Manual de ética aplicada: de la teoría a la práctica. Chile: Universidad Católica de Chile; 2021. 